\title{
Comparison of Atrial Fibrillation Guidelines
}

\author{
Thure Filskov Overvad, M.D. ', Peter Brønnum Nielsen, M.Sc., Ph.D. ', and Torben Bjerregaard Larsen, \\ M.D., Ph.D. ${ }^{1,2}$
}

${ }^{1}$ Aalborg Thrombosis Research Unit, Department of Clinical Medicine, Faculty of Health, Aallborg University, Aalborg, Denmark; ${ }^{2}$ Aallborg Atrial Fibrillation Study Group, Department of Cardiology, Aalborg University Hospital, Aallborg, Denmark.

J Gen Intern Med 30(10): 1404

DOI: $10.1007 / \mathrm{s} 11606-015-3379-2$

(c) Society of General Internal Medicine 2015

$\mathrm{W}$ e welcome the effort by Andrade et al. to investigate the net clinical benefit associated with vitamin $\mathrm{K}$ antagonist (VKA) treatment according to the specific risk factors added by the $\mathrm{CHA}_{2} \mathrm{DS}_{2}$-VASc to the $\mathrm{CHADS}_{2}$ score (vascular disease, age 65-74 and female sex). ${ }^{1}$ We do, however, have some concerns.

First, the authors used data from the now historical NRAF II cohort dating back to more than 15 years ago, which may have non-contemporary rates of thromboembolic events and bleeding. The high overall rate of bleeding of 21.1 per 100 patient-years during VKA treatment in this relatively low bleeding risk population (aged 65-74 years without heart failure, hypertension, diabetes, or previous stroke) raises concern about the quality of anticoagulation control, as reflected by time spend in the therapeutic range (TTR) - and these data are not available. Warfarin should be the drug of choice for stroke prevention only in patients expected to achieve a high TTR of $>70 \%{ }^{2}$ Otherwise, the non-vitamin $\mathrm{K}$ antagonist oral anticoagulants (NOACs) are the preferred first line agents.

Indeed, the use of NOACs may result in a net clinical benefit for patients whose annual risk of stroke is as low as $0.9 \%{ }^{3}$ - these rates are substantially lower than the ischemic stroke rates of 2.9 per 100 patient-years observed in the NRAF II data set. Hence, the authors neglect the impact of the NOACs, notwithstanding their 'old' data, which are not reflective of modern management of atrial fibrillation. ${ }^{4}$

Also, $34.3 \%$ of the $\mathrm{CHADS}_{2}=0$ patients were on concomitant treatment with aspirin. How many of the $\mathrm{CHADS}_{2}=0$ patients on warfarin were using aspirin concomitantly? The combination of aspirin and VKA is generally not recommended in patients with atrial fibrillation, as it increases the risk of bleeding with no further reduction of the thromboembolic burden. ${ }^{5}$ This may have inflated the number of bleeding events attributable to VKA treatment in the study by Andrade.
Second, the authors conclude that adherence to guidelines would entail that 'rates of hemorrhages would rise without a significant reduction in stroke equivalents'. Their main conclusion is based on data with very few events (only one intracranial hemorrhage and nine ischemic strokes), potentially leading to imprecise estimates of event rates.

We suggest that the authors temper their conclusions based on underpowered historical data, potentially limited by concomitant aspirin use and no information about warfarin compliance and TTR during follow-up. Continued investigation into the net clinical benefit associated with anticoagulant treatment across specific risk factor categories is important.

Conflict of Interest: Dr. Larsen has served as an investigator for Janssen Scientific Affairs, LLC and Boehringer Ingelheim, and has been on the speaker bureau for Bayer, BMS/Pfizer, Janssen Pharmaceuticals, Takeda, Roche Diagnostics and Boehringer Ingelheim. Other authors - none declared.

Corresponding Author: Torben Bjerregaard Larsen, M.D., Ph.D.; Aalborg Atrial Fibrillation Study Group, Department of Cardiology, Aalborg University Hospital, Forskningens Hus, Søndre Skovvej 15, 9100 Aalborg, Denmark (e-mail: tobl@rn.dk).

\section{REFERENCES}

1. Andrade AA, Li J, Radford MJ, Nilasena DS, Gage BF. Clinical benefit of American College of Chest Physicians versus European society of cardiology guidelines for stroke prophylaxis in atrial fibrillation. J Gen Intern Med. 2015. doi:10.1007/s11606-015-3201-1.

2. De Caterina R, Husted $\mathbf{S}$, Wallentin $\mathbf{L}$, et al. Vitamin $\mathrm{K}$ antagonists in heart disease: current status and perspectives (Section III): position paper of the ESC working group on thrombosis-task force on anticoagulants in heart disease. Thromb Haemost. 2013;110(6):1087-107. doi:10.1160/ TH13-06-0443.

3. Eckman MH, Singer DE, Rosand J, Greenberg SM. Moving the tipping point: the decision to anticoagulate patients with atrial fibrillation. Circ Cardiovasc Qual Outcomes. 2011;4(1):14-21. doi:10.1161/ CIRCOUTCOMES.110.958108.

4. Banerjee A, Lane DA, Torp-Pedersen C, Lip GY. Net clinical benefit of new oral anticoagulants (dabigatran, rivaroxaban, apixaban) versus no treatment in a "real world" atrial fibrillation population: a modelling analysis based on a nationwide cohort study. Thromb Haemost. 2012;107(3):584-9. doi:10.1160/TH11-11-0784.

5. Flaker GC, Gruber M, Connolly SJ, et al. Risks and benefits of combining aspirin with anticoagulant therapy in patients with atrial fibrillation: an exploratory analysis of stroke prevention using an oral thrombin inhibitor in atrial fibrillation (SPORTIF) trials. Am Heart J. 2006; 152(5):967-73. doi:10. 1016/j.ahj.2006.06.024. 